\title{
Transport mechanisms for the uptake of organic compounds by rice (Oryza sativa) roots
}

\author{
Yu-Hong $\mathrm{Su}^{\text {a,b }}$, Yong-Guan $\mathrm{Zhu}{ }^{\text {a,* }}$ \\ ${ }^{a}$ Research Center for Eco-environmental Sciences, Chinese Academy of Sciences, 18 Shuangqing Road, Beijing 100085, China \\ ${ }^{\mathrm{b}}$ Chemistry Department, Xinjiang University, Urumqi 830046, China
}

Received 20 July 2006; received in revised form 22 October 2006; accepted 1 November 2006

Different organic compounds may be transported via different pathways in plant roots depending on log $K_{\text {ow }}$.

\begin{abstract}
Uptake of six organic compounds, dinitrobenzene (DNB), dinitrotoluene (DNT), lindan (LIN), 1,2,3-triclorobenzene (TCB), phenanthrene (PHN) and pyrene (PYR) by freshly excised rice roots and dead rice roots (heated for 40 min at $105^{\circ} \mathrm{C}$ ) were investigated. Results indicated that the uptake by the two types of roots did not increase proportionally with those in external solution. There appears to be some special chemical function of root cells other than simple absorption by the cells. The contribution of this special function can be roughly estimated by deducting the partition uptake into cells from the total uptake. Both time-dependent uptake data and concentration-dependent uptake curves demonstrate that, DNT and DNB transport is achieved presumably mainly via the symplastic pathway, while PHN and PYR transport mainly via the apoplastic pathway. For LIN and TCB, apoplastic transport pathway plays major roles in the first $2 \mathrm{~h}$ of uptake, then symplastic transport pathway dominates uptake.
\end{abstract}

(C) 2006 Elsevier Ltd. All rights reserved.

Keywords: Transport mechanism; Organic compounds; Rice (Oryza sativa); Apoplastic transport; Symplastic transport

\section{Introduction}

Food crops are susceptible to contamination by various pesticides and organic wastes through foliar or root uptake. Understanding the uptake mechanism of these chemicals by plant roots has key implications for phytoremediation and risk assessment of contaminated agricultural produces. This need has led to a series of investigations on the plant-uptake process in the last 40 years (Lichtenstein, 1960; King et al., 1966; Harris and Sans, 1967; Walker, 1972; Trapp and Matthies, 1995; Burken and Schnoor, 1997; Weiss, 2000; Trapp, 2004; Su and Zhu, 2006). Plants can be exposed to contaminants in different ways. Organic contaminants may enter plant roots by passive and/or active processes and then move

\footnotetext{
* Corresponding author.

E-mail address: ygzhu@rcees.ac.cn (Y.-G. Zhu).
}

in the plant transpiration stream to other plant components (Briggs et al., 1982; Chiou et al., 2001; Li et al., 2005). Passive transport, which proceeds in the direction of decreasing chemical potential, consists of a series of partitions between plant water and plant organic matter within various plant components (Chiou et al., 2001). Accounts of the concentrations of nonionic contaminants in plants in relation to the external concentrations in water (or soil solution) from extensive sources reveal that most of these contaminants enter plants largely via passive process (Vanier et al., 1999, 2001). Active transport, which may proceed against the electro-chemical potential gradient, occurs for certain nutrients and other (inorganic and organic) ions. The magnitude and efficiency of uptake depends on source contaminant concentration, contaminant properties, plant species/composition, exposure time, and other system variables (Lichtenstein, 1960; King et al., 1966; Walker, 1972; Briggs et al., 1983; Li et al., 2002). The plant lipid content may have a significant effect on the 
storage of organic compounds (McLachlan, 1996; Chiou et al., 2001; Li et al., 2005; Barbour et al., 2005).

The foregoing studies indicated that the uptake of nonionic organic compounds by plants roots is mechanistically similar to the chemical partition into nonliving organic matter (Chiou et al., 2001). A series of empirical correlations for selective plant seedlings have been established for estimation of the contaminant partition uptake by specific plant parts from external water (or other media) at nearequilibrium (Briggs et al., 1982, 1983; Trapp et al., 1990; Trapp and Matthies, 1995) or quasi-equilibrium conditions (Chiou et al., 2001). However, there is little knowledge of the roles of cell substrates in root uptake and it is not known from existing studies if there is other function except the partition (or absorption) of organic components in living plant roots.

Nonetheless, the previous studies indicated that sparingly soluble organic compounds were poorly translocated within plants, confined largely in below-ground plant parts (Wild et al., 1992; McCrady et al., 1990); for example, PAHs and $\mathrm{PCDD} /$ Fs concentrate primarily in the peel rather than the inner core of carrots in contaminated soils (Wild and Jones, 1992; Muller et al., 1994). Wild et al. (2005) investigated the uptake and movement of anthracene and phenanthrene from a contaminated growth medium into unmodified living roots of maize and wheat. PAHs were detectable in both cell walls and cell vacuoles. The apoplastic flow through multiple cell walls dominated the translocation of PAHs; only a small fraction of the compounds is transported via the symplastic movement into cellular vacuoles. However, more-soluble organic compounds, such as atrazine ( $\mathrm{Su}$ and $\mathrm{Zhu}, 2006$ ) and TCE (Li et al., 2005), are known to be easily translocated within plants. As such, there is a need to account for the apparently different transport pathways of organic compounds in plant roots.

Understanding the translocation of organic pollutants is essential to the contamination assessment of crops and produces. In the present study, the time-dependent uptake of six organic compounds, dinitrobenzene, dinitrotoluene, lindane, 1,2,3-trichlorobenzene, phenanthrene and pyrene by fresh excised rice roots and dead rice roots (heated for $40 \mathrm{~min}$ at $105^{\circ} \mathrm{C}$ ) were investigated to elucidate the effect of the cell activity on pollutant uptake. Uptake mechanisms were assessed by comparing the uptake isotherms of the compounds between living rice roots, dead un-ground rice roots, and dead ground rice root samples.

\section{Materials and methods}

\subsection{Chemicals}

1,2,3-Triclorobenzene (TCB) (purity, 99\%), lindan (LIN) (97\%), phenanthrene (PHN) (98\%), and pyrene (PYR) (98\%), 1,3-dinitrobenzene (DNB) (99.3\%), and 2,4-dinitrotoluene (DNT) $(99.4 \%)$ were purchased from Aldrich-Sigma. They were all used in root uptake experiments without further purification. The fundamental physicochemical properties of the compounds are given in Table 1.
Table 1

Physicochemical properties of the organic compounds used in experiments ${ }^{\mathrm{a}}$

\begin{tabular}{llllrll}
\hline Compound & Abbrev. & MW & $\rho$ & $\mathrm{mp}$ & $S_{\mathrm{w}}$ & $\log K_{\mathrm{ow}}$ \\
\hline 1,2,3-Trichlorobenzene & TCB & 181.5 & 1.45 & 53 & 16.3 & 4.04 \\
Lindane & LIN & 290.9 & 1.87 & 113 & 7.87 & 3.72 \\
Phenanthrene & PHN & 178.2 & 1.17 & 101 & 1.29 & 4.46 \\
Pyrene & PYR & 202.3 & 1.27 & 156 & 0.135 & 5.18 \\
1,3-Dinitrobenzene & DNB & 168.1 & 1.37 & 90 & 533 & 1.49 \\
2,4-Dinitrotoluene & DNT & 182.1 & 1.52 & 71 & 300 & 1.98 \\
\hline
\end{tabular}

MW, molecular weight; $\rho$, density at room temperature $(\mathrm{g} / \mathrm{mL}) ; \mathrm{mp}$, melting point $\left({ }^{\circ} \mathrm{C}\right) ; S_{\mathrm{w}}$, water solubility at $25^{\circ} \mathrm{C}(\mathrm{mg} / \mathrm{L}) ; K_{\text {ow }}$, octanol-water partition coefficient.

${ }^{a}$ The density $(\rho), \mathrm{mp}, S_{\mathrm{w}}$ and $K_{\mathrm{ow}}$ values are from those cited in Chiou et al. (2005) except those of 1,3-dinitrobenzene from Syracuse Research Corporation database.

\subsection{Preparation of rice roots}

Seeds of China rice Jiahua-1 (Oryza sativa L.) were disinfected in $30 \%$ $\mathrm{H}_{2} \mathrm{O}_{2}$ (wt:wt) solution for $10 \mathrm{~min}$, followed by thorough washing with de-ionized water. The seeds were germinated in moist perlite. Seven days after germination, the seedlings were transferred to a nutrient solution for continuing growth. Four weeks later, uniform seedlings were selected for the uptake experiment. At this time, the fresh weight of rice roots was about $1.0 \mathrm{~g}$. In subsequent experiment, roots were washed three times with distilled water, dried with tissue paper, and then excised at the basal node. After weighing, some of them were quickly put into 100 -ml conical flasks, sealed with glass stoppers, heated for $40 \mathrm{~min}$ at $105{ }^{\circ} \mathrm{C}$, and then cooled. Care was taken during this process to ensure the roots were exposed to open air for a minimal period.

\subsection{Partition into the organic components}

The combined dried rice roots were ground into small particle sizes (passing a 100-mesh sieve with $0.149 \mathrm{~mm}$ aperture), which were subsequently used to determine the contaminant partition coefficients between plant organic matter and water, i.e., the respective $K_{\text {pom }}$ values. In the $K_{\text {pom }}$ determination, fixed quantities of the dried-ground roots were added to a series of water solutions containing different initial concentrations of a given contaminant; the suspensions were equilibrated for $48 \mathrm{~h}$ and the contaminant concentrations in roots and water after this equilibration period were measured to establish the sorption isotherms. This equilibration period was checked to be sufficient for contaminant equilibrium between dry roots and water.

\subsection{Concentration-dependent uptake}

Both fresh rice roots and dead rice roots were quickly rinsed and then placed in $60 \mathrm{ml} 0.01 \mathrm{M} \mathrm{CaCl}_{2}$ solutions containing given concentrations of contaminants (which were dissolved with acetone first, then diluted with $\mathrm{CaCl}_{2}$ solution in the proportion of $2: 1000$ ) and $400 \mathrm{mg} \mathrm{L}^{-1} \mathrm{NaN}_{3}$; bottles were sealed and shaken for $16 \mathrm{~h}$ with a shaker at $25^{\circ} \mathrm{C}$, according to the results of time-dependent uptake. Experimental samples with each treatment were prepared in triplicates. Control solutions containing the test compounds (solutes) but no rice roots were analyzed at the same time to account for the solute loss by handling, volatilization, and degradation. Average system loss was found to be consistently at about $1-5 \%$ of the initial solute concentrations. Contaminant concentrations in initial solution and in water solutions with or without rice roots after experimental period were measured. From these measurements, the uptake concentrations of the contaminants in rice roots were determined based on the mass balance and used to construct the concentration-dependent uptake curve.

\subsection{Time-dependent uptake}

Both fresh rice roots and dead rice roots were quickly rinsed and then placed in $60 \mathrm{ml} 0.01 \mathrm{M} \mathrm{CaCl}_{2}$ water solutions containing given concentration 
of contaminants and $400 \mathrm{mg} \mathrm{L}^{-1} \mathrm{NaN}_{3}$, then the bottles were sealed and shaken for 10, 30, 50, $90 \mathrm{~min}$, and 2, 4, 12, 16, $24 \mathrm{~h}$ with a shaking machine. Each treatment was conducted with three replicates, and a control (water solutions with contaminants proceeded at the same time) to deduce the loss of contaminant by volatilization and degradation.

\subsection{Analyses of contaminants}

Aliquots of water solutions (normally $1-25 \mathrm{~mL}$ ) were extracted for the solutes using $n$-hexane $(0.5-10 \mathrm{~mL})$. Solute concentrations were quantified by gas chromatography using a standard curve established from known solute concentrations in $n$-hexane, run in conjunction with the experimental samples. The concentrations of LIN and TCB in extracts were analyzed with an Agilent 6820 gas chromatograph with a ${ }^{63} \mathrm{Ni}$ electron capture detector (ECD) using a DB-1 capillary column $(0.53 \mathrm{~mm} \times 15 \mathrm{~m}, 0.5 \mu \mathrm{m}$ film thickness), while the concentrations of DNB, DNT, PHN and PYR were analyzed with Agilent 6820 gas chromatograph with a flame ionization detector (FID) using a HP-5 MS capillary column $(0.32 \mathrm{~mm} \times 30 \mathrm{~m}, 0.25 \mu \mathrm{m}$ film thickness $)$.

\subsection{Membrane permeability and lipid content}

$\mathrm{K}^{+}$effluxes from fresh rice roots and dead rice roots were measured to assess the possible changes in membrane permeability caused by heating (Llamas et al., 2000). Rice roots samples were washed twice with cold $1 \mathrm{mM} \mathrm{CaCl}{ }_{2}$ solution to eliminate nutrient solution from the apoplast and then blotted on filter paper. Each root sample was introduced in $10 \mathrm{~mL}$ of fresh $1 \mathrm{mM} \mathrm{CaCl}_{2}$ solution, then incubated for $4 \mathrm{~h}$ at $25^{\circ} \mathrm{C}$ and gently shaken. Each treatment was conducted with three replicates. Aliquots of this solution were taken to measure the $\mathrm{K}^{+}$content by inductively coupled plasma optical emission spectrometry (ICP-OES), Optima 2000 DV (Perkin-Elmer, Wellesley, MA, USA).

The content of lipid-like substances in rice roots was measured using the method described by Barbour et al. (2005).

\section{Results and discussion}

\subsection{Sorption isotherm of organic compounds into rice root particles}

Concentrations of six compounds in dried-ground rice roots (particles passing through a 100-mesh sieve) increased proportionally with concentrations in external solutions. The sorption isotherms of these compounds are listed in Table 2. The sorption isotherms have a linear shape with no significant intercepts, suggesting that the partition into the dried rice root organic matter is the dominant mechanism for the sorption of these compounds. The sorption coefficients with driedroot organic matter $\left(K_{\text {pom }}\right)$ are well correlated with the water solubilities $\left(S_{\mathrm{w}}\right)$ and $K_{\mathrm{ow}}$ of the compounds (Fig. 1):

Table 2

Sorption isotherms of six organic compounds with dried rice-root organic matter (DROM)

\begin{tabular}{lll}
\hline Compound & Isotherm function & $R^{2}$ \\
\hline DNB & $C_{\text {drom }}=16.6 C_{\mathrm{w}}$ & 0.990 \\
DNT & $C_{\text {drom }}=27.2 C_{\mathrm{w}}$ & 0.986 \\
TCB & $C_{\text {drom }}=187 C_{\mathrm{w}}$ & 0.992 \\
LIN & $C_{\text {drom }}=264 C_{\mathrm{w}}$ & 0.997 \\
PHN & $C_{\text {drom }}=1720 C_{\mathrm{w}}$ & 0.977 \\
PYR & $C_{\text {drom }}=9090 C_{\mathrm{w}}$ & 0.975 \\
\hline
\end{tabular}

$\log K_{\text {pom }}=-0.75 \log S_{\mathrm{w}}+3.24 R^{2}=0.99$

$\log K_{\text {pom }}=0.68 \log K_{\text {ow }}+0.06 R^{2}=0.88$

This result indicated that the sorption by dried rice roots of the contaminants occurs predominantly by partitioning into root organic matter, even though the lipid content may be very low (Li et al., 2005; Barbour et al., 2005). In the present study, the lipid content of dried rice roots was found to be $7.05 \pm 0.74 \%$, derived from the lipid content of $0.67 \pm 0.07 \%$ and the water content of $90.5 \%$ for the wet rice roots $(n=8)$.

\subsection{Concentration-dependent uptake}

The concentrations of the six compounds in rice roots increased clearly with the concentrations in external solutions (Figs. 2-6), and the uptake coefficient (the ratio of the compound concentration in roots to that in external solution, $\left.C_{\mathrm{p}} / C_{\mathrm{w}}\right)$ increased with the $K_{\mathrm{ow}}$ value of the compound. Similar empirical correlations for other contaminants in plant roots have also observed (Briggs et al., 1982; Trapp and Matthies, 1995). For the polar organic compounds, such as DNB and DNT, the concentration-dependent uptake curves are linear extending to low concentrations in external solutions. In this case, the uptake coefficients are greater with fresh roots than with dead roots and the intercepts of the curves decreased when the fresh rice roots were heated. Data for DNB are shown in Fig. 2, and similar data for DNT are not shown. As the $K_{\text {ow }}$ of organic compounds increased, the respective uptake coefficients with dead roots surpassed gradually those with the fresh roots (Figs. 2-6), rendering the resulting isotherms with fresh roots a nonlinear shape (Fig. 4).

Based on the results of Wild et al. (2005), the movement of PAHs (PHN and PYR) into the cortex of wheat over a 56-day period was dominated by apoplastic flow through multiple cell walls; only a small amount of the compound was transported

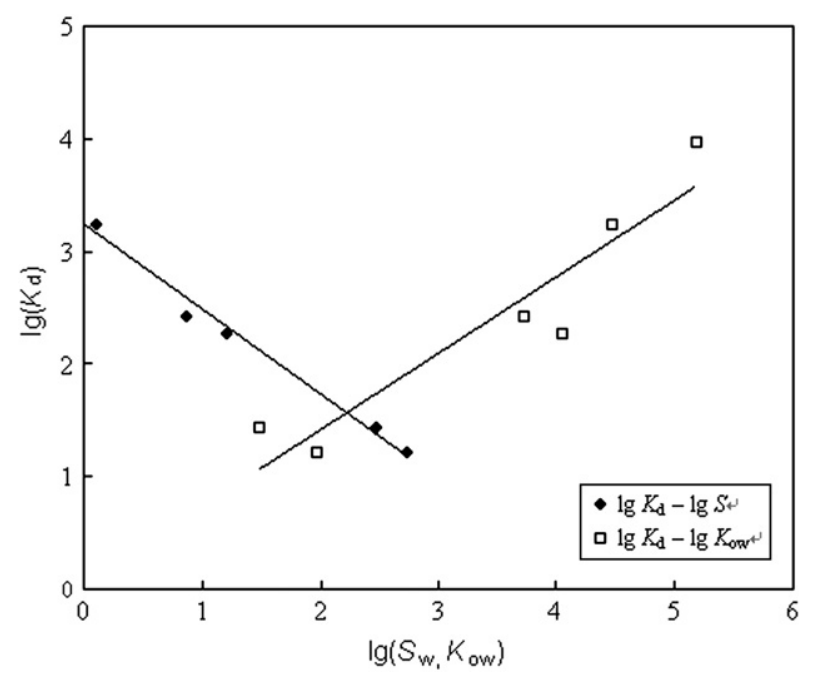

Fig. 1. Relationship between sorption coefficient $\left(K_{\mathrm{d}}\right)$ and water solubility $\left(S_{\mathrm{w}}\right)$ or $K_{\text {ow }}$ of six organic compounds with ground dried rice roots. 


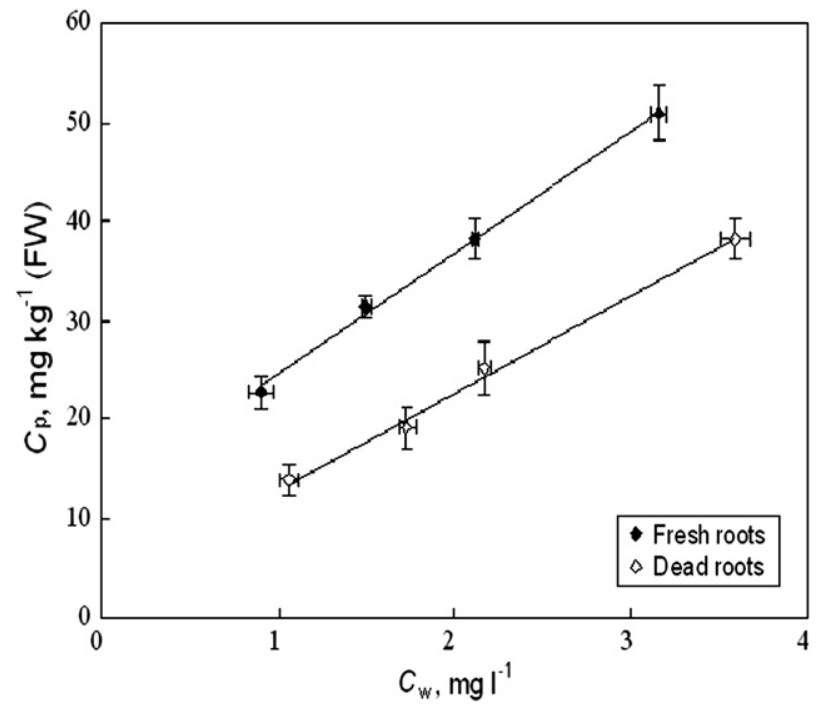

Fig. 2. Concentration-dependent uptake curves of DNB with fresh and dead rice roots. Each point is the average of three replicates. Bars, $\pm 1 \mathrm{SE}$.

into the cellular vacuoles by the symplasmic movement. Apparently, the partition of PAHs into organic substrates of fresh roots was far from equilibrium in a relatively short time $(16 \mathrm{~h})$, and the uptakes were dominated by sorption to cell walls. Our concentration-dependent uptake curves of PHN and PYR into fresh and dead rice roots (Figs. 5 and 6) are consistent with the conclusion of Wild et al. (2005). Here the uptake isotherms of PHN with fresh roots have a nonlinear shape, due possibly to a transport retardation, in which the uptake coefficient $\left(C_{\mathrm{p}} / C_{\mathrm{w}}\right)$ decreases with increasing external concentration. Heating the fresh rice roots increased the permeability of the cell membrane (by about six times), so that the diffusion of organic compounds into root organic components increased, and more PHN and PYR partitioned into plant lipid-like substances, enhancing the partition contribution. As a result, the

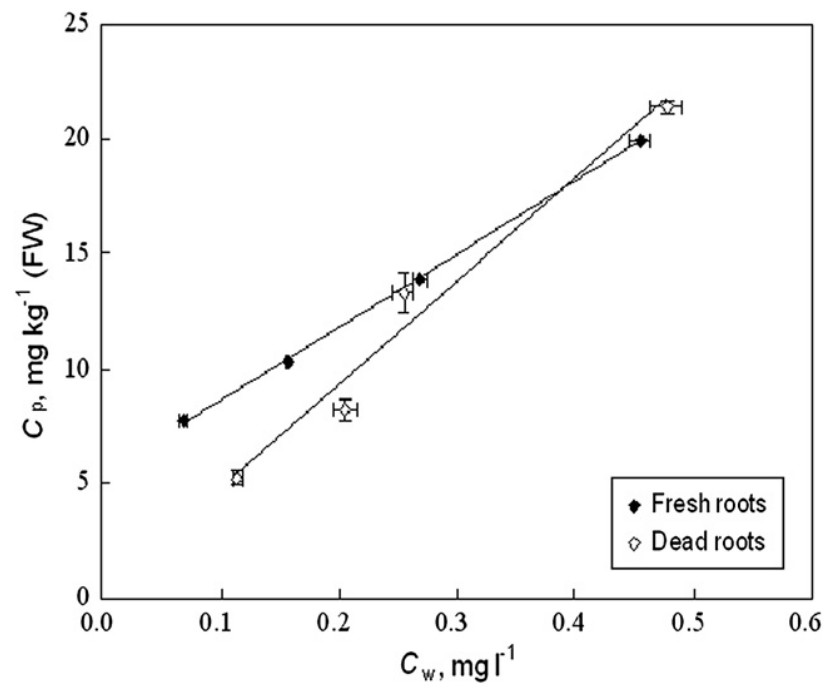

Fig. 3. Concentration-dependent uptake curves of LIN with fresh and dead rice roots. Each point is the average of three replicates. Bars, \pm 1 SE.

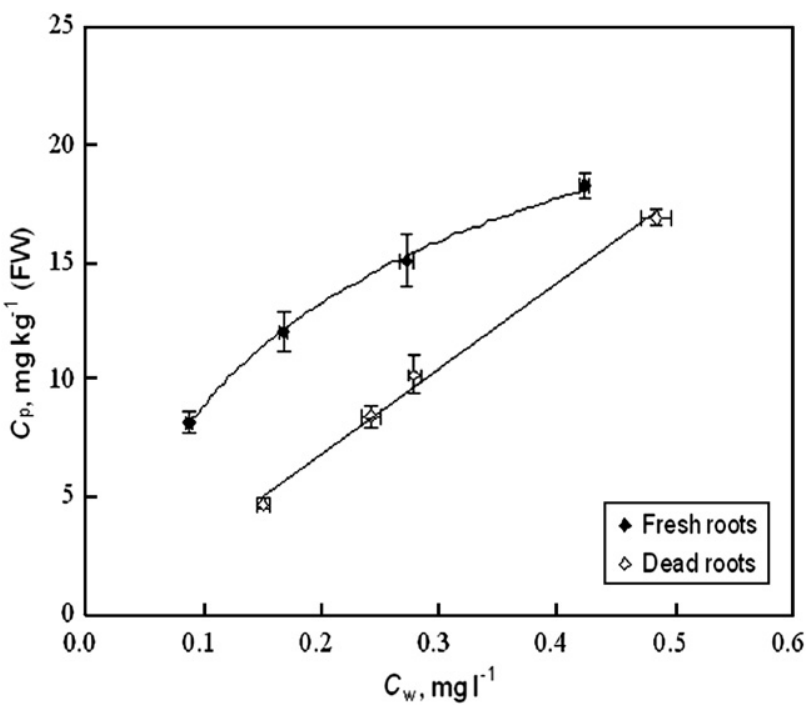

Fig. 4. Concentration-dependent uptake curves of TCB with fresh and dead rice roots. Each point is the average of three replicates. Bars, \pm 1 SE.

uptake of PHN with dead roots is relatively linear, and the capacity is greater than that with the fresh roots.

It is known that uptake of relatively polar (or water-soluble) compounds by live barley roots approaches the equilibrium limits in 24-48 h (Briggs et al., 1982; Chiou et al., 2001). For these compounds, the symplastic pathway likely dominates to transport the compounds into root cells, where the partition into cell substrates plays an important role in the uptake process. Moreover, the heating of rice roots had probably no significant influence on the water transport and hence on the movement of relatively hydrophilic DNT and DNB into root cells with the water flow. However, the higher apparent uptakes of the compounds with the fresh (live) roots, especially at low levels, might have resulted from their specific binding with cell walls and/or the metabolic loss of the compound,

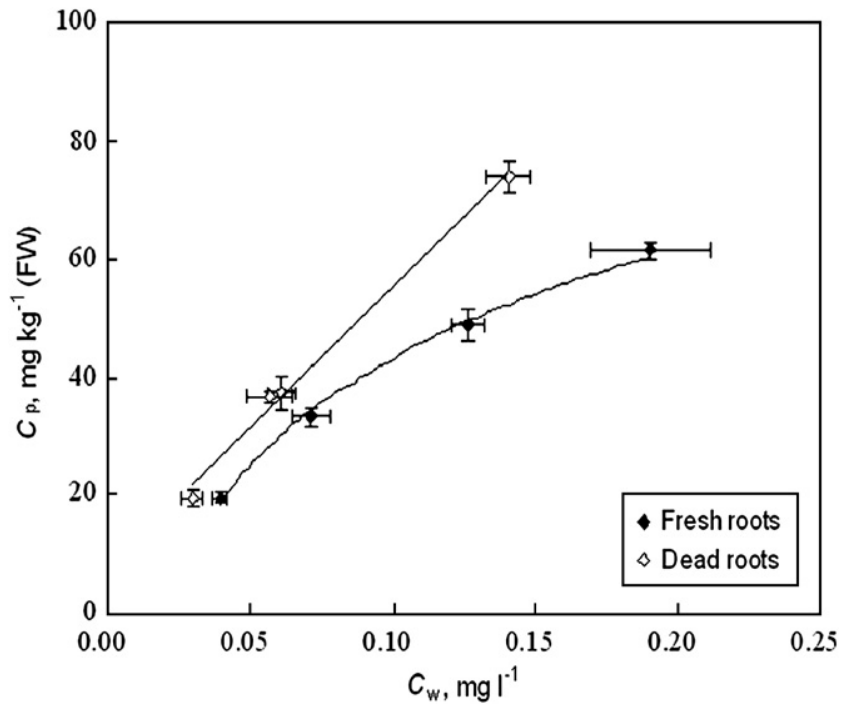

Fig. 5. Concentration-dependent uptake curves of PHN with fresh and dead rice roots. Each point is the average of three replicates. Bars, \pm 1 SE. 


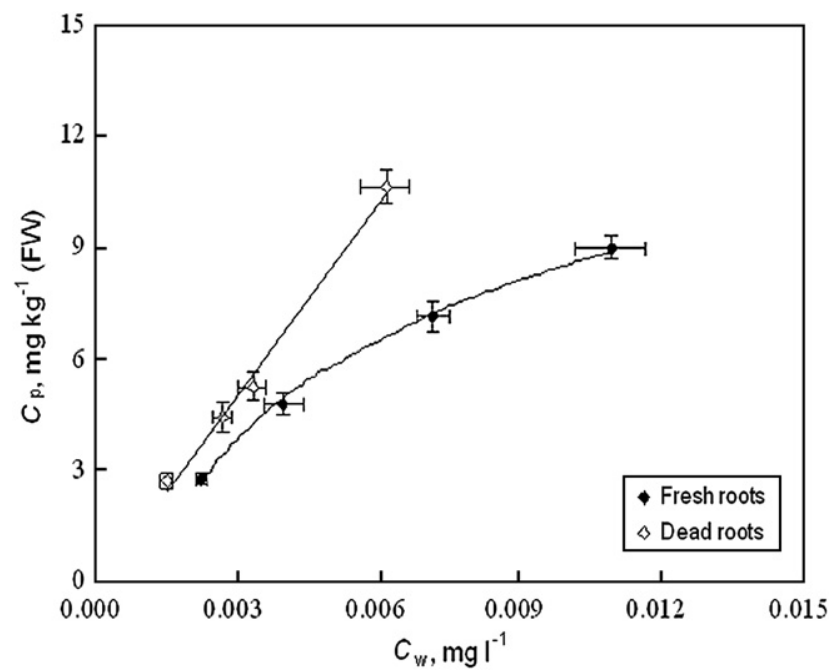

Fig. 6. Concentration-dependent uptake curves of PYR with fresh and dead rice roots. Each point was the average of three replicates. Bars, \pm 1 SE.

because these effects were only possible for live root cells. As a result, the uptake coefficients $\left(C_{\mathrm{p}} / C_{\mathrm{w}}\right)$ of DNB and DNT with live roots are higher than those with the dead roots after a 16-h period (Fig. 2). Proof of the specific binding or the metabolic loss has yet to be elucidated by analyzing the parent and degraded chemical species with root cell substrates.

For the transport of LIN and TCB to rice roots (Figs. 3 and 4), both apoplastic and symplastic pathways might presumably be important. LIN and TCB are far less hydrophilic than DNB and DNT but not extremely lipophilic. To better understand the compound-dependent uptakes of the six compounds, the concentration of a compound in roots are divided into two parts, as shown in Fig. 7, i.e.,

$C_{\mathrm{p}}=C_{\mathrm{a}}+C_{\mathrm{o}}$

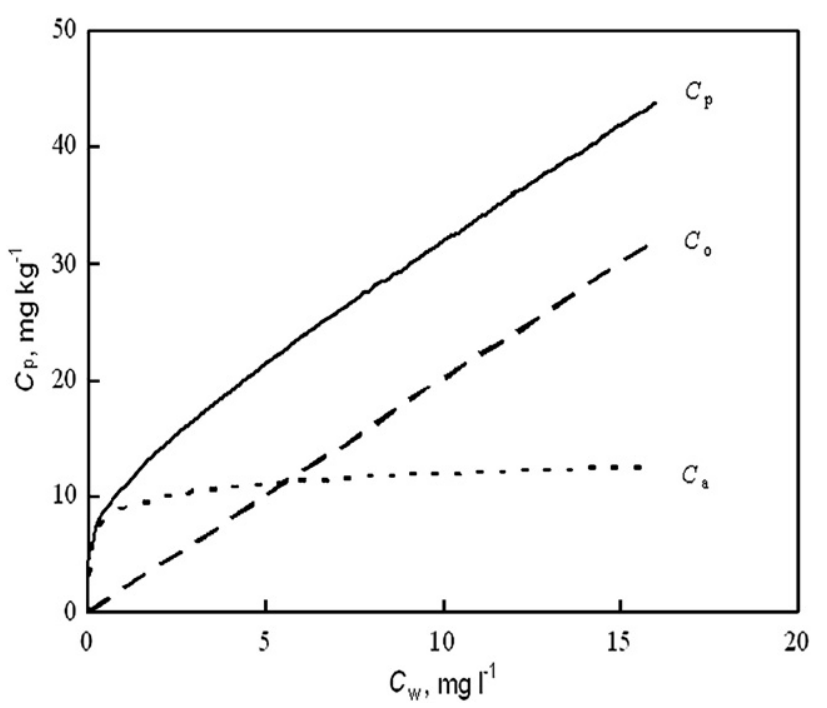

Fig. 7. Composite uptakes of compounds by plant roots. $C_{\mathrm{a}}=$ the special function of cell walls; $C_{\mathrm{o}}=$ the partition with root components; $C_{\mathrm{p}}=$ the total concentration in plant roots. where $C_{\mathrm{p}}$ is the total concentration in roots; $C_{\mathrm{a}}$ is the concentration via function of cell walls (and that for the metabolites), and $C_{\mathrm{o}}$ is the concentration via partitioning into the root organic matter. $C_{\mathrm{o}}$ could be estimated using the root composition and the $K_{\text {ow }}$ of the compound (Li et al., 2005) or determined directly from the measured partition coefficient with excised roots (Chiou et al., 2001; $\mathrm{Su}$ and $\mathrm{Zhu}, 2006$ ). The $C_{\mathrm{a}}$ at a given $C_{\mathrm{p}}$ may be estimated by deducting $C_{\mathrm{o}}$ from $C_{\mathrm{p}}$.

\subsection{Time-dependent uptake}

When the rice roots were exposed to external solution, the concentrations of polar organic compounds (such as DNB and DNT) in rice roots increased quickly in the first $10 \mathrm{~min}$, as shown for DNB in Fig. 8. The similar results for DNT are not shown. The uptake coefficients $\left(C_{\mathrm{p}} / C_{\mathrm{w}}\right)$ of DNB with the fresh rice roots were slightly higher than those with the dead fresh roots, presumably because the water uptake by fresh rice roots accelerated the transport of compounds into the root cells. The uptake coefficient of DNB in fresh roots gradually decreased with the uptake time after $10 \mathrm{~min}$ to $90 \mathrm{~min}$, and then increased with the uptake time after $2 \mathrm{~h}$ to $24 \mathrm{~h}$. For the nonpolar organic compounds, such as PHN and PYR, their concentrations in rice roots always increased with uptake time, and their uptake coefficients were far greater with dead roots than with fresh roots even during a short uptake time (Fig. 9); the same effect with PYR was not shown. Results of time-dependent uptake suggested that the uptake of DNB and PHN by rice roots was mediated by different transport pathways, which was consistent with the conclusion of concentration-dependent uptake.

Polar DNB seemed to move into rice roots mainly through the symplastic path and entered the xylem quickly, due to its higher solubility and lower molecular weight (i.e., the greater diffusion coefficient). The uptake coefficient decreased with

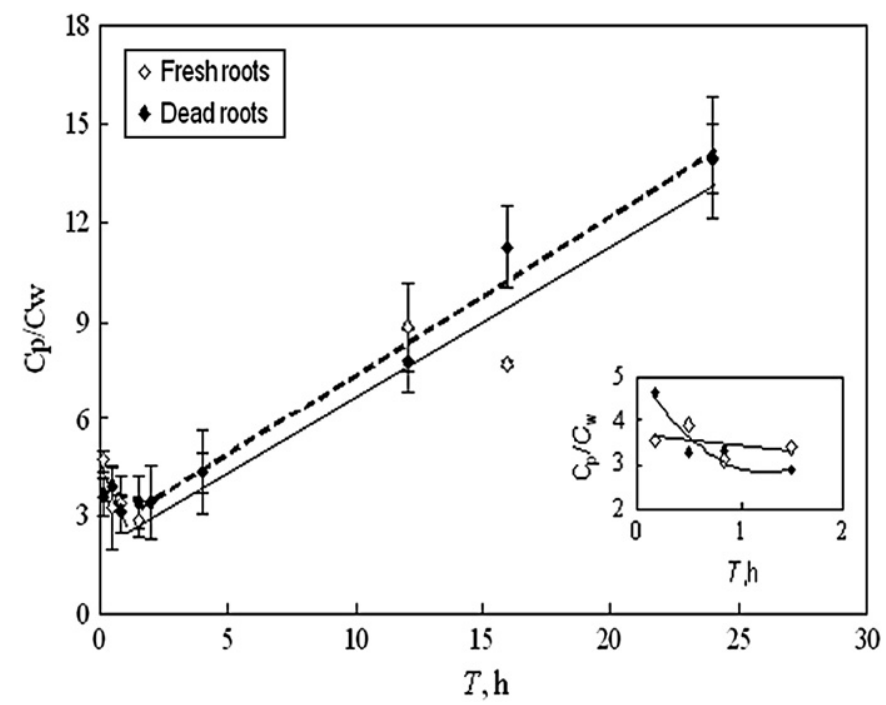

Fig. 8. Time-dependent uptake coefficients $\left(C_{\mathrm{p}} / C_{\mathrm{w}}\right)$ of DNB with fresh rice roots and dead rice roots. Each point is the average of three replicates. Bars, $\pm 1 \mathrm{SE}$. 


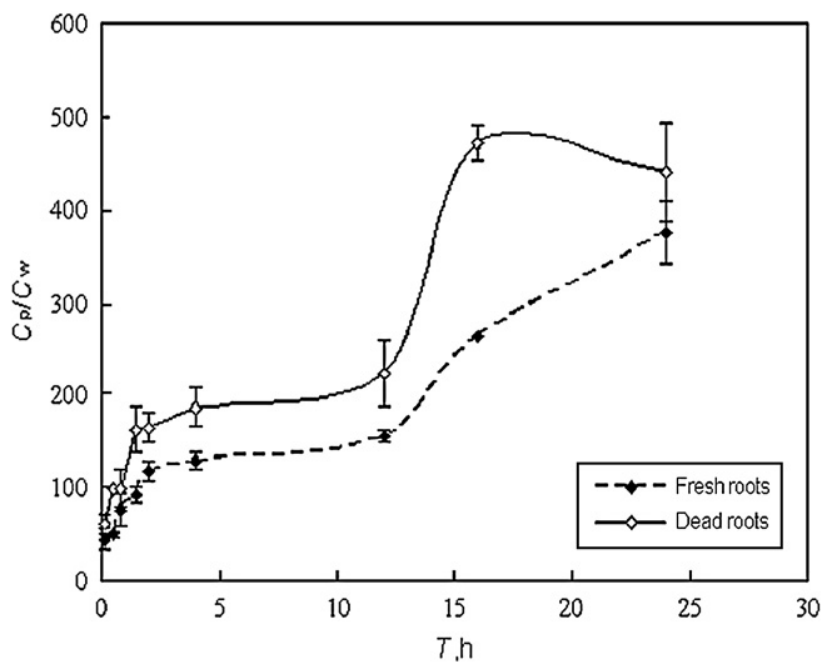

Fig. 9. Time-dependent uptake coefficients $\left(C_{\mathrm{p}} / C_{\mathrm{w}}\right)$ of PHN with fresh rice roots and dead rice roots. Each point is the average of three replicates. Bars, $\pm 1 \mathrm{SE}$.

the uptake time from $10 \mathrm{~min}$ to $90 \mathrm{~min}$ just because a portion of the compound moved away from fresh roots with water flow into the xylem. For nonpolar PHN and PYR, the apoplastic pathway appeared to play a more important role in the rootsystem transport. The movement of water and solutes through the apoplast was dominated by the diffusion into root cell walls and the motion through cell walls between cells. The cell wall was more permeable than the protoplast to water and its solutes (Marschner, 1995). Results from a previous study indicated that 5\% PHN was detected in the cell vacuoles and $95 \%$ in the cell walls (Wild et al., 2005) after a 56-day uptake by wheat, implying that the apoplastic transport is the dominant pathway for PHN through the roots. Meanwhile, in addition to the movement through the apoplast, there is probably a small loss to the symplast, based on smaller amounts of compounds observed with the cell vacuole (Wild et al., 2005). With the root sample heated at $105^{\circ} \mathrm{C}$ for $40 \mathrm{~min}$, the membrane penetrability of the compound with dead roots is

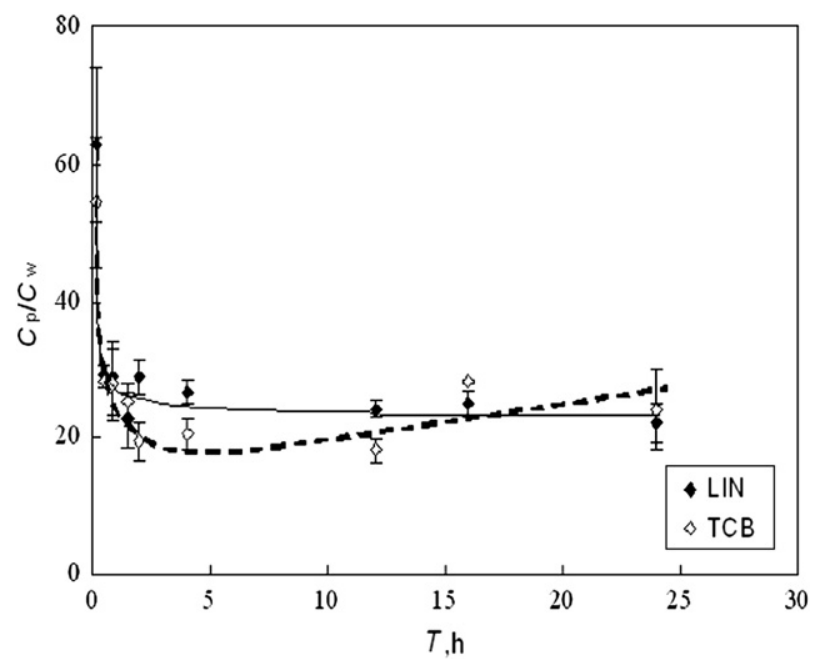

Fig. 10. Time-dependent uptake coefficients $\left(C_{\mathrm{p}} / C_{\mathrm{w}}\right)$ of LIN and TCB with fresh rice roots. Each point is the average of three replicates. Bars, $\pm 1 \mathrm{SE}$. presumably enhanced over that with the fresh roots, leading to the increased loss of PAHs in the symplast, and the concentrations of PHN and PYR in dead roots became greater than those in fresh roots.

For TCB and LIN, both apoplastic and symplastic pathways appeared to be important in their movement into fresh roots. The equilibrium seemed to have been reached for LIN when the uptake time was more than $2 \mathrm{~h}$ by fresh rice roots (Fig. 10). This result was consistent with the conclusion of Hinman and Klaine (1992) in a similar study. The uptake coefficients of LIN and TCB with fresh rice roots decreased quickly initially with time, just like those of DNB and DNT, then changed slowly with time thereafter, whereas the coefficients with dead rice roots increased slowly with the uptake time, not shown in the figure.

\section{Conclusion}

Results from the current study provided additional information regarding the mechanisms of root uptake of organic compounds with different polarity, and suggested that root cell wall may have a significant role in the movement of organic compounds in the root-system. The contributions from the cell wall could be estimated by the uptake isotherm using a Langmuir model, while inputs of root water and organic matter contents and contaminant partition coefficients with (dry) root organic fractions enable the respective contaminant partition limits to be determined for evaluating the plant-uptake efficiency. Over a short uptake time, the partition contribution of a contaminant decreased with increasing $K_{\text {ow }}$ of the compound; i.e., the higher is $K_{\text {ow }}$ for the compound. These results explain the facts that sparingly soluble organic compounds in soils usually are accumulated in plant roots because it is difficult for them to be transported to shoots when their $K_{\text {ow }}$ are very high. The symplastic pathway in fresh roots dominated the transport of polar organic compounds (such as DNB), while apoplastic pathway dominated the transport of nonpolar organic compounds (such as PHN).

\section{Acknowledgements}

This research was financially supported by the Ministry of Science and Technology (2002CB410808), the Chinese Academy of Sciences (KZCX3-SW-431).

\section{References}

Briggs, G.G., Bromilow, R.H., Evans, A.A., 1982. Relationships between lipophilicity and root uptake and translocation of non-ionised chemicals by barley. Pesticide Science 13, 495-504.

Briggs, G.G., Bromilow, R.H., Evans, A.A., Williams, M., 1983. Relationships between lipophilicity and the distribution of non-ionised chemicals barley shoots following uptake by roots. Pesticide Science 14, 492-500.

Barbour, J.P., Smith, J.A., Chiou, C.T., 2005. Sorption of aromatic organic pollutants to grasses from water. Environmental Science and Technology 39, 8369-8373.

Burken, J.G., Schnoor, J.L., 1997. Uptake and metabolism of atrazine by poplar trees. Environmental Science Technology 31, 1399-1404. 
Chiou, C.T., Sheng, G., Manes, M., 2001. A partition-limited model for the plant uptake of organic contaminants from soil and water. Environmental Science and Technology 35, 1437-1444.

Chiou, C.T., Schmedding, D.W., Manes, M., 2005. Improved prediction of octanol-water partition coefficients from water solubilities and molar volumes. Environmental Science and Technology 39, 8840-8846.

Hinman, M.L., Klaine, S.J., 1992. Uptake and translocation of selected organic pesticides by the roots aquatic plant Hydrilla verticillata Royle. Environmental Science and Technology 26, 609-613.

Harris, C.R., Sans, W.W., 1967. Absorption of organochlorine insecticide residues from agricultural soils by root crops. Journal of Agriculture and Food Chemistry 15, 861-863.

King, R.L., Clark, N.A., Hemken, R.W., 1966. Distribution, movement, and persistence of heptachlor and its epoxide in alfalfa plants and soil. Journal of Agriculture and Food Chemistry 14, 62-65.

Li, H., Sheng, G., Sheng, W., Xu, O., 2002. Uptake of trifluralin and lindane from water by ryegrass. Chemosphere 48, 335-341.

Li, H., Sheng, G., Chiou, C.T., Xu, O., 2005. Relation of organic contaminant equilibrium sorption and kinetic uptake in plants. Environmental Science and Technology 39, 4864-4870.

Lichtenstein, E.P., 1960. Insecticidal residues in various crops grown in soils treated with abnormal rates of aldrin and heptachlor. Journal of Agriculture and Food Chemistry 8, 448-451.

Llamas, A., Ullrich, C., Sanz, A., 2000. $\mathrm{Ca}^{2+}$ effects on transmembrane electrical potential difference, respiration and membrane permeability of rice (Oryza sativa L.) roots. Plant and Soil 219, 21-28.

Marschner, H., 1995. Mineral Nutrition of Higher Plants. Academic Press, London, pp. 68-75.

McLachlan, M.S., 1996. Bioaccumulation of hydrophobic chemicals in agricultural food chains. Environmental Science and Technology 30, 252-259.

Muller, J.F., Hulster, A., Papke, O., Ball, M., Marschner, H., 1994. Transfer of PCDD/PCDF from contaminated soils into carrots lettuce and peas. Chemosphere 29, 2175-2181.
McCrady, J.K., McFarlane, C., Gander, L.K., 1990. The transport and fate of 2,3,7,8-TCDD in soybean and corn. Chemosphere 21, 359-376.

$\mathrm{Su}$, Y.H., Zhu, Y.G., 2006. Bioconcentration of atrazine and chlorophenols into roots and shoots of rice seedlings. Environmental Pollution 139, 32-39.

Trapp, S., Matthies, M., Scheunert, I., Topp, E.M., 1990. Modeling the bioconcentration of organic chemicals in plants. Environmental Science and Technology 24, 1246-1252.

Trapp, S., 2004. Plant uptake and transport model for neutral and ionic chemicals. Environmental Science and Pollution Research 11, 33-39.

Trapp, S., Matthies, M., 1995. Generic one-compartment model for uptake of organic chemicals by foliar vegetation. Environmental Science and Technology 29, 2333-2338.

Vanier, C., Planas, D., Sylvestre, M., 1999. Empirical relationships between polychlorinated biphenyls in sediments and submerged rooted macrophytes. Canadian Fishery and Aquatic Sciences 56, 1792-1800.

Vanier, C., Planas, D., Sylvestre, M., 2001. Equilibrium partition theory applied to PCBs in macrophytes. Environmental Science and Technology $35,4830-4833$.

Wild, S.R., Jones, K.C., 1992. Organic chemicals in the environment. Polynuclear aromatic hydrocarbons uptake by carrots grown in sludge-amended soil. Journal of Environmental Quality 21, 217-225.

Wild, E., Dent, J., Tomas, G.O., Jones, K.C., 2005. Direct observation of organic contaminant uptake, storage, and metabolism with plant roots. Environmental Science and Technology 39, 3695-3702.

Wild, S.R., Berrow, M.L., McGrath, S.P., Jones, K.C., 1992. Polynuclear aromatic hydrocarbons in crops from long-term field experiments amended with sewage sludge. Environmental Pollution 76, 25-32.

Weiss, P., 2000. Vegetation/soil distribution of semivolatile organic compounds in relation to their physicochemical properties. Environmental Science and Technology 34, 1707-1714.

Walker, A., 1972. Availability of atrazine to plants in different soils. Pesticide Science 3, 139-148. 